\title{
Pressure Pain Threshold in Musculoskeletal Disorders
}

\author{
Kas İskelet Hastalıklarında Basınç Ağrı Eşiği
}

\author{
Özbil Korkmaz GÜREL ${ }^{1}$, Aslıhan TARAKTAŞ ${ }^{2}$, Duygu KURTULUŞ ${ }^{3}$, Cengiz BAHADIR ${ }^{4}$ \\ 1. Physical Medicine and Rehabilitation Department, VM Medicalpark Hospital, Kocaeli \\ 2. Physical Medicine and Rehabilitation Department, Fatih Sultan Mehmet Training and Research Hospital, Istanbul \\ 3. Physical Medicine and Rehabilitation Department, Umraniye Training and Research Hospital, Istanbul \\ 4. Physical Medicine and Rehabilitation Department, Vocational School of Health, Hasan Kalyoncu University, Gaziantep
}

\section{ABSTRACT}

Aim: Pain is the most significant symptom in musculoskeletal disorders. General hypersensitivity to pain is often associated with conditions of chronic pain. In this study we compared pain degrees of different musculoskeletal disease groups by pain pressure threshold and visual analog scale.

\begin{abstract}
Materials and Method: Patients diagnosed with ankylosing spondylitis $(n=34)$, fibromyalgia $(n=30)$, myofascial pain syndrome $(n=33)$, osteoporosis $(n=34)$, generalized osteoarthritis $(n=34)$ and rheumatoid arthritis $(n=34)$ and healthy subjects $(n=30)$ were included in the study. Beck depression inventory was used for psychological evaluation. Visual analog scale (VAS) was used to quantify clinical pain. PPT measurements made from the areas that generally not showing involvement of disease: at middle deltoid, middle ulna, hypothenar eminence, thumb, mid-tibia, and quadriceps femoris.
\end{abstract}

Results: VAS score for clinical pain ranged from $4.76 \pm 3.15$ in ankylosing spondylitis to $7.44 \pm 2.42$ in fibromyalgia. Fibromyalgia consistently had the lowest PPT across all sites of measurements indicating increased pain sensitivity. Myofascial pain syndrome and ankylosing spondylitis were the only diseases that did not show greater sensitivity to pain compared to healthy controls. Osteoporosis patients also reported an average clinical pain of 6.09 \pm 3.23 on VAS, and showed general tenderness regardless of presence of verified fractures. Overall, female gender, advanced age, depression and NSAID use correlated with lower PPT.

Conclusions: The level of pain sensitivity may provide a clue regarding the mechanism and treatment options of musculoskeletal disorders.

Keywords: pressure pain threshold; ankylosing spondylitis; myofascial pain syndrome; osteoporosis; arthritis; fibromyalgia

\section{$\ddot{O Z Z E T}$}

Amaç: Ağrı kas iskelet sistemi bozukluklarında en belirgin semptomdur. Ăgrıya karşı genel aşırı duyarlılık sıklıkla kronik a ̆̆rı koşullarlyla ilişkilidir. Bu çalışmada, farklı kas-iskelet sistemi hastalık gruplarının ăgrı derecelerini, ă̆rı basınç eşiği ve görsel analog skala ile karşılaştırdık.

Yöntem ve Gereçler: Çalışmaya ankilozan spondilit $(n=$ 34), fibromiyalji $(n=30)$, miyofasiyal ağr sendromu $(n=$ $33)$, osteoporoz $(n=34)$, jeneralize osteoartrit $(n=34)$ ve romatoid artrit $(n=34)$ tanısı alan hastalar ve sağlıklı kişiler $(n=30)$ dahil edildi. Psikolojik değerlendirme için Beck depresyon envanteri, klinik ağrıyı ölçmek için görsel analog skala (VAS) kullanıldı. PPT ölçümleri hastalık tutulumu göstermeyen alanlardan yapıldl: orta deltoid, orta ulna, hipotenar belirginlik, başparmak, orta tibia ve kuadriseps femoris.

Bulgular: Klinik ağrı için VAS skoru, ankilozan spondilitte $4.76 \pm 3.15$, fibromiyaljide $7.44 \pm 2.42$ idi. Fibromiyalji, ağrl duyarlılığının arttığını gösteren tüm ölçüm yerlerinde tutarlı olarak en düşük PPT'ye sahipti. Miyofasyal ă̆r sendromu ve ankilozan spondilit, ağrlya sağllkl kontrollerle karşılaştırıldı̆̆ında daha fazla duyarlılık göstermeyen tek hastalıkt. Osteoporoz hastalart ayrica VAS'da ortalama klinik ağrı $6.09 \pm 3.23$ ve doğrulanmıș kırıkların varlığına bakılmaksızın genel hassasiyet göstermiştir. Genel olarak, kadin cinsiyet, ileri yaş, depresyon ve NSAID kullanımı düşük PPT ile koreleydi.

Sonuç: A ğrı duyarlılığının düzeyi, kas-iskelet bozukluklarının mekanizması ve tedavi seçenekleri hakkında ipucu sağlayabilir.

Anahtar Kelimeler: basınç ăgrı eşiği; ankilozan spondilit; myofasial ağr sendromu; osteoporoz; artrit; fibromiyalji

\section{Contact:}

Corresponding Author: Aslıhan TARAKTAŞ

Address: Physical Medicine and Rehabilitation Department, Fatih Sultan Mehmet Training and Research Hospital, Istanbul, Turkiye

Phone Number: +90 (216) 5783000

E-mail: aslihantaraktas@gmail.com

Submitted: 15.02.2017

Accepted: 16.03.2017 


\section{INTRODUCTION}

Chronic pain is an integral part of most musculoskeletal disorders, having a negative impact on the quality of life of the patients. Although pain is regarded as the body's response to noxious stimuli, its presentation, frequency and intensity varies considerably between disease groups and individuals. Certain conditions may be associated with a general hypersensitivity to pain or tenderness, while others may be specific to the affected area. Quantitative assessment of experimentally evoked pain has been used to reveal differences between genders and age groups of healthy individuals as well as disease groups. These differences may have important implications in terms of diagnosis, disease management, prediction of treatment response and understanding the underlying pain mechanisms (1).

In this study, we compared pain pressure threshold (PPT) in areas of the body normally not affected by the disease between ankylosing spondylitis, fibromyalgia, myofascial pain, osteoporosis, generalized osteoarthritis, rheumatoid arthritis and healthy control subjects to assess the pain perception degrees, presence and extent of general hypersensitivity to mechanical stimulus.

\section{MATERIALS and METHODS}

\section{Study design and patients}

This was a prospective study comparing pain pressure threshold of different musculoskeletal disorders associated with chronic pain. Patients followed in our Physical Medicine and Rehabilitation Outpatient Clinic with a clear diagnosis of one of the following diseases were included in the study: rheumatoid arthritis $(n=34)$, ankylosing spondylitis $(n=34)$, fibromyalgia $(n=30)$, myofascial pain syndrome in the trapezius muscle $(n=33)$, osteoporosis $(n=34)$ and generalized osteoarthritis $(n=34)$. In addition, thirty healthy control subjects were included in the study.

Rheumatoid arthritis was diagnosed based on the 1987 American College of Rheumatology (ACR) classification criteria (2). Ankylosing spondylitis was diagnosed based on the modified New York criteria (3). Fibromyalgia was diagnosed based on the 1990 ACR criterias (4).

The presence of myofascial trigger points was determined using the diagnostic criteria described by Simons et al (5). Osteoporosis was diagnosed according to WHO definition (6). Generalized osteoarthritis was defined as bilateral involvement of fingers or involvement of the spine and both femorotibial joints (7).

Patients fulfilling diagnostic criteria for more than one of the above musculoskeletal disorders were excluded from the study. Measurement of bone mineral density (BMD) was performed by using Dual Energy X-ray Absorptiometry (DEXA). Measurements were taken in all cases and the patients who had osteoporosis and one of the any other diseases were excluded also. In addition, subjects were excluded if pregnant, younger than 18 years of age, having cognitive or mental problems, history of surgery in the upper or lower extremity or any disease that may affect upper or lower extremity performance such as polyneuropathy, vasculitis, dermatological diseases, neurovascular skin diseases, peripheral vascular disease, spinal cord injury, malignancy, burn or loss of sensation. Patients who had disease involvement in the measurement area were excluded.

The study was approved by the institutional review board. Written informed consent was obtained from all participants.

\section{Procedures}

General (clinical) pain was evaluated using the visual analog scale (VAS), where patients were asked to mark the level of pain related to their disease on a $10 \mathrm{~cm}$ lateral scale with one end indicating no pain and the other end indicating worst possible pain.

Pain pressure threshold was measured using a digital algometry (JTECH Medical Algometer Commander - USA). Patients were familiarized with the algometry and a demonstration was carried out on a different part of the body unrelated to the sites of measurement (thenar area). Patients were asked to say "stop" when they feel pain first to indicate pain threshold. A $1 \mathrm{~cm}^{2}$ probe was used and values are presented in Newton (N). Pressure was increased at a speed of $10 \mathrm{~N} / \mathrm{s}$ until patient reported pain and to confirm reliability three readings were taken from each site with $5 \mathrm{sec}$ intervals between readings and the mean value was used in the analysis. All measurements were carried outby the same physician who was blind to the patient groups, in the same room and room temperature, using the same equipment and. Measurements were carried out bilaterally and always in the same order: middle deltoid, middle ulna, hypothenar eminence, thumb, mid tibia, and quadriceps femoris muscle. 
Beck Depression Inventory (BDI) was completed by all subjects (8). BDI is a 21 -item questionnaire, where a score of 21 or above represents depression.

\section{Statistical analysis}

Statistical analysis was performed using NCSS (Number Cruncher Statistical System) 2007 and PASS 2008 Statistical Software (Utah, USA). Data was summarized using descriptive statistics (mean, standard deviation, percentage). For variables with normal distribution one-way ANOVA was used to compare means and post-hoc Tukey HDS test was used to determine the groups differing from each other. For variables with non-normal distribution Kruskal Wallis was used to compare means and Mann Whitney U test was used to determine the groups differing from each other. In two group comparisons Student t test and Mann Whitney U test were used for normal and nonnormally distributed variables, respectively. Pearson correlation analysis and Spearman's rho correlation analysis were used for normal and non-normally distributed variables, respectively. Chi-square test was used for analysis of categorical variables. Results were evaluated within $95 \%$ confidence interval and the level of significance was set at $\mathrm{p}<0.05$.

\section{RESULTS}

Two hundred and twenty-nine subjects participated in the study. Patients were diagnosed with one of six musculoskeletal diseases including ankylosing spondylitis $(n=34)$, fibromyalgia syndrome $(\mathrm{n}=30)$, myofascial pain syndrome $(n=33)$, osteoporosis $(n=34)$, generalized osteoarthritis $(n=34)$, and rheumatoid arthritis $(n=34)$. In addition, a group of he- althy subjects was included as control $(n=30)$. Due to the variety of diseases, age and gender distribution of study groups were significantly different (Table 1). Majority of the patients were women in all groups except for ankylosing spondylitis (due to the nature of disease most patients composed of males) and healthy control groups. Osteoporosis, generalized osteoarthritis and rheumatoid arthritis patients were significantly older than the rest. Median disease duration was longest for ankylosing spondylitis ( 9 years), followed by rheumatoid arthritis (7 years), generalized osteoarthritis (6 years), osteoporosis and fibromyalgia (3 years) and myofascial pain syndrome (2 years). Depression was more common in fibromyalgia, myofascial pain and rheumatoid arthritis patients (Table 1). On visual analog scale the level of pain experienced by the patient was lowest for ankylosing spondylitis $(4.76 \pm 3.15)$ and rheumatoid arthritis (5.55 \pm 2.55$)$. Non-steroidal anti-inflammatory drug (NSAID) use was highest among ankylosing spondylitis (68\%) and rheumatoid arthritis (76\%) patients (Table 1). Anti TNF treatment was used by $41 \%$ of the ankylosing spondylitis and $15 \%$ of the rheumatoid arthritis patients. Antidepressant use was not very common ranging between 3 and 13\% in disease groups (Table 1).

For pain pressure threshold measurements, a digital algometry was used on mid deltoid, midline ulna, hypothenar eminence, thumb, mid tibia, and quadriceps femoris, always in that order bilateral. Whole body PPT was calculated as the mean value from all measurements. Fibromyalgia patients consistently had the lowest PPT across all sites of measurements. Generalized osteoarthritis patients also had low PPT compared to healthy controls across all sites.

Table 1: Patient characteristics.

\begin{tabular}{|l|c|c|c|c|c|c|c|c|}
\hline & $\begin{array}{c}\text { HC } \\
\mathbf{n}=\mathbf{3 0}\end{array}$ & $\begin{array}{c}\text { AS } \\
\mathbf{n}=\mathbf{3 4}\end{array}$ & $\begin{array}{c}\mathbf{F S} \\
\mathbf{n}=\mathbf{3 0}\end{array}$ & $\begin{array}{c}\text { MPS } \\
\mathbf{n}=\mathbf{3 3}\end{array}$ & $\begin{array}{c}\text { OS } \\
\mathbf{n}=\mathbf{3 4}\end{array}$ & $\begin{array}{c}\text { GOA } \\
\mathbf{n}=\mathbf{3 4}\end{array}$ & $\begin{array}{c}\text { RA } \\
\mathbf{n}=\mathbf{3 4}\end{array}$ & $\boldsymbol{p}$ \\
\hline Age, ${ }^{1}$ years (mean \pm SD) & $37 \pm 12$ & $33 \pm 8$ & $40 \pm 10$ & $39 \pm 11$ & $62 \pm 9$ & $67 \pm 9$ & $48 \pm 12$ & 0.001 \\
\hline Female, ${ }^{2} \mathrm{n}(\%)$ & $14(47)$ & $13(38)$ & $30(100)$ & $27(82)$ & $32(94)$ & $32(94)$ & $28(82)$ & 0.001 \\
\hline Disease duration, ${ }^{3}$ years & - & $9.8 \pm 6.9$ & $3.8 \pm 3.4$ & $3.8 \pm 5.4$ & $3.8 \pm 4.1$ & $10.0 \pm 9.0$ & $9.9 \pm 9.1$ & 0.001 \\
\hline Depression, ${ }^{4} \mathrm{n}(\%)$ & $0(0)$ & $10(29)$ & $14(47)$ & $15(46)$ & $9(26)$ & $8(24)$ & $12(35)$ & 0.001 \\
\hline VAS, $^{5}$ mean $\pm S D$ & - & $4.76 \pm 3.15$ & $7.44 \pm 2.42$ & $6.55 \pm 2.78$ & $6.09 \pm 3.23$ & $7.05 \pm 2.69$ & $5.55 \pm 2.55$ & $<0.01$ \\
\hline NSAID use, ${ }^{6} \mathrm{n}(\%)$ & - & $23(68)$ & $13(43)$ & $6(18)$ & $10(29)$ & $15(44)$ & $26(76)$ & 0.001 \\
\hline Anti TNF use, $\mathrm{n}(\%)$ & - & $14(41)$ & - & - & - & - & $5(15)$ & 0.015 \\
\hline Antidepressant, $\mathrm{n}(\%)$ & - & $0(0)$ & $4(13)$ & $3(9)$ & $3(9)$ & $1(3)$ & $2(6)$ & 0.303 \\
\hline
\end{tabular}

HC: healthy control; AS: ankylosing spondylitis; FS: fibromyalgia syndrome; MPS: myofascial pain syndrome; OS: osteoporosis; GOA: generalized osteoarthritis; RA: rheumatoid arthritis.

1 , OS and GOA mean age significantly higher than the rest $(p<0.001)$; RA mean age significantly higher than $\mathrm{HC}, \mathrm{AS}, \mathrm{FS}, \mathrm{MPS}(\mathrm{p}<0.05)$

2, Significantly more women in FS, MPS, OS, GOA and RA ( $p<0.001)$

3, AS, GOA, RA disease duration significantly longer compared to FS, MPS, OS ( $p<0.001$ )

4, FS, MPS and RA patients had significantly more depression compared to the rest $(p<0.01)$

5 , VAS score of AS significantly lower than FS $(p=0.001)$, MPS $(p=0.025)$, GOA $(p=0.003)$; VAS score of RA significantly lower than FS ( $p=0.002)$ and GOA $(p=0.003)$

6, NSAID use in AS and RA significantly higher than the rest $(p<0.01)$; NSAID use in MPS significantly lower than the rest except for OS ( $<<0.01)$. 
Table 2: Pressure pain threshold (PPT) values (mean \pm SD) at different body sites.

\begin{tabular}{|c|c|c|c|c|c|c|c|c|}
\hline & $\mathrm{HC}$ & AS & FS & MPS & OS & GOA & RA & $p$ \\
\hline Mid deltoid $^{1}$ & $4.47 \pm 1.54$ & $4.57 \pm 1.60$ & $3.15 \pm 0.82$ & $5.02 \pm 1.59$ & $3.94 \pm 0.89$ & $4.02 \pm 1.24$ & $4.42 \pm 1.40$ & 0.001 \\
\hline Midline ulna ${ }^{2}$ & $5.32 \pm 1.40$ & $4.59 \pm 1.74$ & $3.44 \pm 0.82$ & $5.15 \pm 1.60$ & $4.03 \pm 1.03$ & $3.96 \pm 1.24$ & $4.22 \pm 1.39$ & 0.001 \\
\hline Hypothenar eminence ${ }^{3}$ & $5.50 \pm 1.71$ & $4.64 \pm 1.78$ & $3.71 \pm 1.00$ & $4.97 \pm 1.86$ & $4.44 \pm 1.02$ & $3.89 \pm 1.45$ & $4.04 \pm 1.61$ & 0.001 \\
\hline Thumb ${ }^{4}$ & $4.43 \pm 1.17$ & $3.55 \pm 1.23$ & $2.57 \pm 0.58$ & $3.72 \pm 1.35$ & $3.25 \pm 0.70$ & $2.97 \pm 1.18$ & $2.87 \pm 1.16$ & 0.001 \\
\hline Mid tibia ${ }^{5}$ & $4.80 \pm 1.60$ & $3.76 \pm 1.11$ & $2.91 \pm 0.77$ & $4.34 \pm 1.55$ & $3.56 \pm 0.91$ & $3.18 \pm 1.07$ & $3.53 \pm 1.33$ & 0.001 \\
\hline Quadriceps femoris ${ }^{6}$ & $6.36 \pm 2.29$ & $5.89 \pm 1.96$ & $3.59 \pm 0.83$ & $5.76 \pm 1.83$ & $4.49 \pm 1.28$ & $3.98 \pm 1.38$ & $4.65 \pm 1.76$ & 0.001 \\
\hline Whole body PPT ${ }^{7}$ & $5.15 \pm 1.50$ & $4.50 \pm 1.40$ & $3.23 \pm 0.64$ & $4.83 \pm 1.43$ & $3.95 \pm 0.80$ & $3.67 \pm 1.08$ & $3.96 \pm 1.25$ & 0.001 \\
\hline
\end{tabular}

HC: healthy control; AS: ankylosing spondylitis; FS: fibromyalgia syndrome; MPS: myofascial pain syndrome; OS: osteoporosis; GOA: generalized osteoarthritis; RA: rheumatoid arthritis.

1, FS significantly lower than HC, AS, MPS and RA ( $p<0.01)$. OS and GOA significantly lower than MPS $(p<0.05)$

2, FS significantly lower than HC $(p<0.01), A S(p<0.05)$ and MPS $(p<0.01)$. OS and GOA significantly lower than HC and MPS ( $<<0.05)$. RA significantly lower than $\mathrm{HC}(\mathrm{p}<0.05)$

3, FS significantly lower than HC $(p<0.01)$ and MPS $(p<0.05)$. GOA and RA significantly lower than HC $(p<0.01)$

4, FS significantly lower than HC, MPS and AS ( $p<0.01)$. GOA and RA significantly lower than HC ( $<<0.01)$ and MPS $(p<0.05)$. AS and OS significantly lower than $\mathrm{HC}(\mathrm{p}<0.05)$

5, FS and GOA significantly lower than HC and MPS ( $p<0.01)$. AS, OS, RA significantly lower than $H C(p<0.05)$.

6, FS, GOA and OS significantly lower than HC ( $p<0.01)$, MPS $(p<0.05)$ and $A S(p<0.05)$. RA significantly lower than HC ( $<<0.01)$ and $A S(p<0.05)$.

7, FS significantly lower than HC, MPS and AS ( $p<0.01)$. OS, GOA and RA significantly lower than HC $(p<0.01)$ and MPS $(p<0.05)$.

Table 3: PPT score correlation with age, disease duration and VAS.

\begin{tabular}{|l|c|c|c|c|c|c|}
\hline & \multicolumn{2}{|c|}{ Age } & \multicolumn{2}{c|}{ Disease duration } & \multicolumn{2}{c|}{ VAS } \\
\hline HC & $\mathbf{r}$ & $\boldsymbol{p}$ & $\mathbf{r}$ & $\boldsymbol{p}$ & $\mathbf{r}$ & - \\
\hline AS & -0.079 & 0.680 & - & - & - & 0.176 \\
\hline FS & 0.148 & 0.402 & 0.204 & 0.247 & 0.238 & 0.237 \\
\hline MPS & -0.075 & 0.694 & -0.280 & 0.134 & 0.223 & 0.770 \\
\hline OS & -0.017 & 0.923 & -0.026 & 0.885 & 0.053 & 0.680 \\
\hline GOA & 0.111 & 0.531 & 0.061 & 0.732 & 0.073 & 0.145 \\
\hline RA & -0.028 & 0.876 & 0.157 & 0.377 & 0.255 & 0.303 \\
\hline All subjectst & 0.416 & $0.014 *$ & -0.097 & 0.586 & -0.182 & $0.045^{*}$ \\
\hline
\end{tabular}

HC: healthy control; AS: ankylosing spondylitis; FS: fibromyalgia syndrome; MPS: myofascial pain syndrome; OS: osteoporosis; GOA: generalized osteoarthritis; RA: rheumatoid arthritis.

$* \mathrm{p}<0.05$

+ All subjects did not include healthy controls for disease duration and VAS.

Table 4: Mean PPT scores by gender, presence of depression and NSAID use.

\begin{tabular}{|c|c|c|c|c|c|c|c|c|c|}
\hline & \multicolumn{3}{|c|}{ Gender (male/female) } & \multicolumn{3}{|c|}{ Depression (yes/no) } & \multicolumn{3}{|c|}{ NSAID use (yes/no) } \\
\hline & $\mathbf{n}$ & Mean \pm SD & $p$ & n & Mean \pm SD & $p$ & n & Mean \pm SD & $p$ \\
\hline \multirow{2}{*}{$\mathrm{HC}$} & 16 & $5.74 \pm 1.65$ & \multirow{2}{*}{$0.020 *$} & & & & & & \\
\hline & 14 & $4.47 \pm 0.98$ & & & & & & & \\
\hline \multirow{2}{*}{ AS } & 21 & $4.74 \pm 1.26$ & \multirow{2}{*}{0.184} & 10 & $4.21 \pm 1.75$ & \multirow{2}{*}{0.496} & 23 & $4.55 \pm 1.25$ & \multirow{2}{*}{0.897} \\
\hline & 13 & $4.11 \pm 1.57$ & & 24 & $4.62 \pm 1.25$ & & 11 & $4.41 \pm 1.74$ & \\
\hline \multirow{2}{*}{ FS } & 0 & - & \multirow{2}{*}{-} & 14 & $3.21 \pm 0.69$ & \multirow{2}{*}{0.884} & 13 & $3.36 \pm 0.59$ & \multirow{2}{*}{0.615} \\
\hline & 30 & $3.23 \pm 0.64$ & & 16 & $3.25 \pm 0.62$ & & 17 & $3.13 \pm 0.68$ & \\
\hline \multirow{2}{*}{ MPS } & 6 & $4.97 \pm 1.81$ & \multirow{2}{*}{0.455} & 15 & $4.98 \pm 1.43$ & \multirow{2}{*}{0.600} & 6 & $4.04 \pm 1.02$ & \multirow{2}{*}{0.112} \\
\hline & 27 & $4.80 \pm 1.37$ & & 18 & $4.70 \pm 1.45$ & & 27 & $5.00 \pm 1.46$ & \\
\hline \multirow{2}{*}{ OS } & 2 & $4.56 \pm 0.05$ & \multirow{2}{*}{-} & 9 & $4.14 \pm 0.91$ & \multirow{2}{*}{0.740} & 10 & $3.62 \pm 0.88$ & \multirow{2}{*}{0.199} \\
\hline & 32 & $3.92 \pm 0.82$ & & 25 & $3.89 \pm 0.77$ & & 24 & $4.10 \pm 0.75$ & \\
\hline \multirow{2}{*}{ GOA } & 2 & $4.84 \pm 0.35$ & \multirow{2}{*}{-} & 8 & $3.25 \pm 1.23$ & \multirow{2}{*}{0.180} & 15 & $3.85 \pm 1.07$ & \multirow{2}{*}{0.340} \\
\hline & 32 & $3.60 \pm 1.07$ & & 26 & $3.80 \pm 1.02$ & & 19 & $3.53 \pm 1.10$ & \\
\hline \multirow{2}{*}{ RA } & 6 & $4.79 \pm 1.59$ & \multirow{2}{*}{0.086} & 12 & $3.35 \pm 1.01$ & \multirow{2}{*}{$0.040^{*}$} & 26 & $3.89 \pm 1.27$ & \multirow{2}{*}{0.685} \\
\hline & 28 & $3.78 \pm 1.13$ & & 22 & $4.29 \pm 1.27$ & & 8 & $4.17 \pm 1.27$ & \\
\hline \multirow{2}{*}{ All subjects } & 53 & $5.07 \pm 1.47$ & \multirow{2}{*}{$0.001 *$} & 68 & $3.90 \pm 1.36$ & \multirow{2}{*}{$0.039 *$} & 93 & $3.95 \pm 1.15$ & \multirow{2}{*}{$0.030^{*}$} \\
\hline & 176 & $3.91 \pm 1.16$ & & 161 & $4.30 \pm 1.30$ & & 136 & $4.34 \pm 1.43$ & \\
\hline
\end{tabular}

HC: healthy control; AS: ankylosing spondylitis; FS: fibromyalgia syndrome; MPS: myofascial pain syndrome; OS: osteoporosis; GOA: generalized osteoarthritis; RA: rheumatoid arthritis. 
Osteoporosis patients had low PPT in the arm and moderately low PPT in the leg, while rheumatoid arthritis patients had low PPT in the hand and moderately low PPT in the leg. PPT of ankylosing spondylitis patients were mostly close to the PPT values of healthy subjects with a significant difference detected only on the mid tibia readings. Myofascial pain syndrome patients had the highest PPT among different patient groups with no significant difference from healthy subjects at any sites of measurement (Table 2).

The effect of age, disease duration and actual clinical pain (VAS score) on PPT was assessed using correlation analysis. There was a moderate positive correlation between age and PPT in rheumatoid arthritis patients (r: 0.416, $\mathrm{p}=0.014$ ), but a weak negative correlation was observed for all subjects ( $\mathrm{r}:-0.136, \mathrm{p}=0.039$ ) (Table 3). PPT was not correlated with disease duration, while it showed a weak negative correlation with VAS when all patients were considered ( $\mathrm{r}:-0.133, \mathrm{p}=0.045)$ (Table 3 ).

PPT was significantly higher in men compared to women $(5.07 \pm 1.47$ vs. $3.91 \pm 1.16$, $p=0.001)$. A similar difference was seen in the healthy control group, but not in ankylosing spondylitis, myofascial pain or rheumatoid arthritis groups. The effect of gender on PPT could not be measured on the other disease groups as the number of men was insufficient for statistical analysis. Patients with depression had significantly lower PPT scores in the rheumatoid arthritis group $(3.35 \pm 1.01$ vs. $4.29 \pm 1.27, \mathrm{p}=0.040)$ and in the overall analysis of all subjects $(3.90 \pm 1.36$ vs. $4.30 \pm 1.30$, $\mathrm{p}=0.039$ ). NSAID users had lower PPT in the overall analysis of all subjects $(3.95 \pm 1.15$ vs. $4.34 \pm 1.43, p=0.030$ ) but no significant difference was detected in the analysis of individual disease groups.

\section{DISCUSSION}

In this study, we compared general pain sensitivity of patients with a variety of musculoskeletal disorders based on measurements at unaffected body sites. This is the first study which compares PPT in six different frequent diseases and healthy individuals.

The VAS is a well known subjective pain scale with simple application. VAS improved long time ago, has been found to be valid and reliable tool for assessing pain relief and pain intensity (9). International Association for the Study of Pain (1986) outlined the pain threshold as "the minimum intensity of a stimulus that is perceived as painful" (10). PPT is a reliable test for hyperalgesia in superficial body structures $(11,12)$.

Our results showed a clear difference in pain sensitivity between inflammatory joint disorders. AS patients had no evidence of tenderness in unaffected body sites, while RA and GOA patients had overall tenderness. Previous studies comparing pressure pain threshold in AS and RA patients also concluded that in contrast to RA, there is no generalized tenderness in AS patients (13-15).

Differences in the presentation of these arthritic diseases may account for the differences in pain perception. AS is manifested as enthesitis and is characterized by spinal involvement. On the other hand, RA begins at the synovium and involves the extremities. Also, genetics may play a role through increased susceptibility to pain in RA compared to AS.

In the Gerecz-Simon et al., study hip or knee OA patients were compared with AS, RA and healthy controls. In their study PPT of OA patients were higher than healthy controls and RA, similar to AS patients. However, subsequent studies conducted on knee OA patients determined decreased PPT near the affected knee as well as at distant body sites suggesting central sensitization (16-19). Similarly, our patients with generalized OA also showed tenderness across all the tested body sites.

Fibromyalgia is a chronic muscle pain disease characterized by widespread allodynia and/or hyperalgesia (20). A diagnostic criterion for fibromyalgia involves pain sensitivity to a pressure of $4 \mathrm{~kg}$ at eleven out of eighteen tender points.

However, it is established that tender points are not the source of pain, rather they are anatomically more sensitive spots to be used in diagnosis (21). We found the lowest PPT scores in fibromyalgia patients for all body sites, indicating general tenderness in accordance with previous studies $(22,23)$. The underlying mechanism for tenderness in fibromyalgia is thought to involve central sensitization and impaired pain modulation in addition to peripheral sensitization (20).

As expected PPT was higher in MPS compared to FS, even though the clinical pain scored by VAS were not significantly different between these groups. Although both syndromes involve muscle tissue and can be found concomitantly in some patients, MPS is a regional 
pain syndrome characterized by trigger point in a taut band, in contrast to the diffuse pain experienced in FS (24).

As far as we know this is the first study investigating pressure pain threshold in osteoporosis patients. Although osteoporosis is often described as a silent disease, osteoporotic pain has a serious impact on the patient's quality of life (25). Chronic back pain in osteoporosis patients is usually related to vertebral compression fractures resulting in deformities in the spine. In this study, clinical pain of osteoporosis patients were comparable to the other chronic pain conditions studied and generalized sensitivity to pain was observed compared to healthy control subjects.

One limitation of this study is that disease groups and healthy control subjects were not age and gender matched due to the differences in demographics of the diseases. Comparison of pain perception between younger and older age groups show varying results based on the methodology used to inflict experimental pain.

Most studies conducted on healthy individuals support an increase in pain threshold with advanced age (26-28). In contrast, a weak negative correlation suggesting lower PPT with advanced age was determined when all subjects were considered in our study. Moreover, OS and GOA, two groups composed of patients with advanced age had significantly lower PPT compared to the younger groups.

Similarly, studies show that there is a gender bias in pain perception such that women have a lower threshold to experimental pain stimuli $(29,30)$. While it could be argued that a more balanced representation of men in healthy control and AS groups may account for the higher PPT values, equally high PPT values of MPS group composed predominantly of women patients contradicts this line of reasoning.

In conclusion, perception of pain in general is not affected in AS and MPS, while hypersensitivity is seen in RA, GOA, OS, and FS. Overall, female gender, advanced age, depression and NSAID use correlated with lower PPT. A weak negative correlation was detected between VAS and PPT when all patients were considered, but no significant correlation was present within the disease groups. Long-term chronic pain may lead to overall tenderness via central and peripheral sensitization and impaired pain modulation. Intrinsic hypersensitivity to pain may also play a role in chronic pain disorders.

\section{REFERENCES}

1. Edwards RR, Sarlani E, Wesselmann U, Fillingim $R B$ (2005) Quantitative assessment of experimental pain perception: multiple domains of clinical relevance. Pain 114 (3):315-319.

2. Arnett FC, Edworthy SM, Bloch DA, McShane DJ, Fries JF, Cooper NS, Healey LA, Kaplan SR, Liang MH, Luthra HS, et al. (1988) The American Rheumatism Association 1987 revised criteria for the classification of rheumatoid arthritis. Arthritis Rheum 31 (3):315-324.

3. Van der Linden S, Valkenburg HA, Cats A (1984) Evaluation of diagnostic criteria for ankylosing spondylitis. A proposal for modification of the New York criteria. Arthritis Rheum 27 (4):361-368.

4. Wolfe F, Smythe HA, Yunus MB, Bennett RM, Bombardier C, Goldenberg DL, Tugwell P, Campbell SM, Abeles M, Clark P, et al. (1990) The American College of Rheumatology 1990 Criteria for the Classification of Fibromyalgia. Report of the Multicenter Criteria Committee. Arthritis Rheum 33 (2):160-172.

5. Simons DG, Travell J, Simons L. (1999) Myofascial pain and dysfunction: the trigger point manual, vol 1. 2nd edn. Baltimore, Williams \& Wilkins, pp. 23-34.

6. Kanis JA, Melton LJ, 3rd, Christiansen C, Johnston CC, Khaltaev N (1994) The diagnosis of osteoporosis. J Bone Miner Res 9 (8):1137-1141.

7. Dougados M, Nakache JP, Gueguen A (1996) Criteria for generalized and focal osteoarthritis. Rev Rhum Engl Ed 63 (9):569-575.

8. Beck AT, Steer RA (1984) Internal consistencies of the original and revised Beck Depression Inventory. $J$ Clin Psychol 40 (6):1365-1367.

9. McCormimack HM, Horne DJ, Sheather S. Clinical applications of visual analogue scales: a critical review. Psychol Med 1988;18:1007-19

10. International Association for the Study of Pain (IASP). Clasification of chronic pain, descriptions of chronic pain syndromes and definitions of pain terms. Amsterdam: Elsevier, 1986

11. Nie H,Arendt-Nielsen L, Andersen H, etal.Temporal summation of pain evoked by mechanical stimulation in deep and superficial tissue. J Pain 2005;6:348-55

12. Rombaut L, Scheper M, De Wandele I, et al. Chronic pain in patients with hypermobility type of EhlerDanlos syndrome: evidence for generalied hyperalgesia. Clin.Rheumatol 2014.

13. Huskisson EC, Hart FD (1972) Pain threshold and arthritis. Br Med J 4 (5834):193-195.

14. Incel NA, Erdem HR, Ozgocmen S, Catal SA, Yorgancioglu ZR (2002) Pain pressure threshold values in ankylosing spondylitis. Rheumatol Int 22 (4):148-150. 
15. Gerecz-Simon EM, Tunks ER, Heale JA, Kean WF, Buchanan WW (1989) Measurement of pain threshold in patients with rheumatoid arthritis, osteoarthritis, ankylosing spondylitis, and healthy controls. Clin Rheumatol $8(4): 467-474$.

16. Arendt-Nielsen L, Nie H, Laursen MB, Laursen BS, Madeleine P, Simonsen OH, Graven-Nielsen T (2010) Sensitization in patients with painful knee osteoarthritis. Pain 149 (3):573-581.

17. Bajaj P, Graven-Nielsen T, Arendt-Nielsen L (2001) Osteoarthritis and its association with muscle hyperalgesia: an experimental controlled study. Pain 93 (2): 107-114.

18. Imamura M, Imamura ST, Kaziyama HH, Targino RA, Hsing WT, de Souza LP, Cutait MM, Fregni F, Camanho GL (2008) Impact of nervous system hyperalgesia on pain, disability, and quality of life in patients with knee osteoarthritis: a controlled analysis. Arthritis Rheum 59 (10): 1424-1431.

19. Lee YC, Lu B, Bathon JM, Haythornthwaite JA, Smith MT, Page GG, Edwards RR (2010) Pain sensitivity and pain reactivity in osteoarthritis. Arthritis Care Res (Hoboken).

20. Nielsen LA, Henriksson KG (2007) Pathophysiological mechanisms in chronic musculoskeletal pain (fibromyalgia): the role of central and peripheral sensitization and pain disinhibition. Best Pract Res Clin Rheumatol 21 (3):465-480.

21. Marques AP, Ferreira EA, Matsutani LA, Pereira CA, Assumpcao A (2005) Quantifying pain threshold and quality of life of fibromyalgia patients. Clin Rheumatol 24 (3):266-271.
22. Granges $G$, Littlejohn $G$ (1993) Pressure pain threshold in pain-free subjects, in patients with chronic regional pain syndromes, and in patients with fibromyalgia syndrome. Arthritis Rheum 36 (5):642-646.

23. Lautenbacher S, Rollman GB, McCain GA (1994) Multi-method assessment of experimental and clinical pain in patients with fibromyalgia. Pain 59 (1):45-53.

24. Staud R (2007) Future perspectives: pathogenesis of chronic muscle pain. Best Pract Res Clin Rheumatol 21 (3):581-596.

25. Lips P, van Schoor NM (2005) Quality of life in patients with osteoporosis. Osteoporos Int 16 (5):447-455.

26. Edwards RR, Fillingim RB (2001) Age-associated differences in responses to noxious stimuli. J Gerontol A Biol Sci Med Sci 56 (3):M180-185.

27. Gibson SJ, Helme RD (2001) Age-related differences in pain perception and report. Clin Geriatr Med 17 (3):433-456, v-vi.

28. Jensen R, Rasmussen BK, Pedersen B, Lous I, Olesen J (1992) Cephalic muscle tenderness and pressure pain threshold in a general population. Pain 48 (2): 197-203.

29. Fillingim RB (2000) Sex, gender, and pain: women and men really are different. Curr Rev Pain 4 (1):24-30.

30. Riley JL, 3rd, Robinson ME, Wise EA, Myers CD, Fillingim RB (1998) Sex differences in the perception of noxious experimental stimuli: a meta-analysis. Pain 74 (2-3):181-187. 